\title{
Mudanças na assistência ao idoso após promulgação do Estatuto do Idoso segundo profissionais de hospital geriátrico*
}

\author{
CHANGES IN THE CARE OF THE ELDERLY AFTER THE ENACTMENT OF THE ELDERLY \\ STATUTE ACCORDING TO PROFESSIONALS OF A GERIATRIC HOSPITAL
}

CAMBIOS EN ASISTENCIA AL ANCIANO DESPUÉS PROMULGACIÓN DEL
ESTATUTO DEL ANCIANO SEGÚN PROFESIONALES DE HOSPITAL GERIÁTRICO

Maristela Santini Martins ${ }^{1}$, Maria Cristina Komatsu Braga Massarollo²

\section{RESUMO}

Este estudo objetivou conhecer o contato da equipe multiprofissional com o Estatuto do Idoso e qual a interferência dessa Lei na assistência ao idoso institucionalizado. O cenário do estudo foi um Hospital Geriátrico de São Paulo, onde residem 297 idosos. Participaram 35 profissionais integrantes da equipe multiprofissional da Instituição que responderam a um questionário composto de perguntas abertas e fechadas. Os resultados foram divididos em categorias e submetidos à análise descritiva. Destacou-se que $68,6 \%$ dos profissionais acreditam estar ocorrendo mudanças na assistência, mesmo que lentamente, após a promulgação da Lei, e que elas ocorreram na equipe multiprofissional, que buscou especialização específica, melhorando a assistência; nas instituições que se adaptaram para atender às especificidades dos idosos; nos próprios idosos e em suas famílias que, sentindo-se respaldados pela Lei, passaram a reivindicar mais os seus direitos.

\section{DESCRITORES}

Direitos dos idosos.

Envelhecimento.

Assistência a idosos.

\begin{abstract}
This study was aimed at finding out how an interdisciplinary team deals with the Elderly Statute and how it interfered in the care of institutionalized elderly. The setting was a geriatric hospital in São Paulo where 297 elderly people reside. Thirty-five professionals from the facility's interdisciplinary team took part in the study and answered a questionnaire with open and close questions. Results were divided into categories and submitted to a descriptive analysis. It was observed that $68.6 \%$ of the professionals thought that after the enactment of the Statute there have been changes in the care provided, even if slowly, and that they occurred in the interdisciplinary staff, which went after specialization in order to improve care; in the facilities, which adapted so as to attend to the needs of the elders; and in the elderly people themselves and in their families, whom, feeling protected by the law, increased the demands for their rights.
\end{abstract}

\section{KEY WORDS}

Aged rights.

Aging.

Old age assistance.

\section{RESUMEN}

En este estudio se tuvo como objetivo conocer el contacto del equipo multiprofesional con el Estatuto del anciano y la interferencia de la ley en la asistencia al anciano institucionalizado. El escenario del estudio fue un Hospital Geriátrico de Sao Paulo, donde residen 297 ancianos. Participaron 35 profesionales integrantes del equipo multiprofesional de la institución los cuales respondieron a un cuestionario compuesto de preguntas abiertas y cerradas. Los resultados fueron divididos en categorías y sometidos al análisis descriptivo. El $68,6 \%$ de los profesionales consideran que está ocurriendo cambios en la asistencia, aunque lentamente, después de la promulgación de la ley, y que ellos se produjeron en el equipo multiprofesional, buscando especialización específica, mejorando así la asistencia en las instituciones, que se adaptaron para atender las especificidades de los ancianos, en los propios ancianos y en sus familias, los que sintiéndose respaldados por la ley pasaron a reivindicar más sus derechos.

\section{DESCRIPTORES}

Derechos de los ancianos.

Envejecimiento.

Asistencia a los ancianos.

\footnotetext{
* Monografia apresentada ao I Curso de Especialização em Gerenciamento de Serviços de Saúde, oferecido pela EEUSP, 2005. ${ }^{1}$ Enfermeira da Irmandade da Santa Casa de Misericórdia de São Paulo - Hospital Geriátrico e de Convalescentes Dom Pedro II. São Paulo, SP, Brasil. maristelasanti@usp.br ${ }^{2}$ Enfermeira, Professora Associada da Escola de Enfermagem da Universidade de São Paulo. São Paulo, SP, Brasil
} 


\section{INTRODUÇÃO}

A população de idosos é muito peculiar em suas necessidades. Relatos antigos, na história mundial, já expressavam preocupações quanto aos cuidados, ao relacionamento familiar e às questões éticas no processo de envelhecimento. Podem ser citadas as obras De Senectude (Saber Envelhecer) de Cícero(1), escrita há mais de 2000 anos, e Rei Lear de Willian Shakespeare(2), publicada originalmente em $1623^{(1-2)}$.

O crescimento desta população, em números absolutos e relativos, é um fenômeno mundial e está ocorrendo de forma sem precedentes. Em 1950, eram cerca de 204 milhões de idosos no mundo e, em 1998, quase cinco décadas depois, esse contingente alcançava 579 milhões de pessoas, um crescimento de quase oito milhões de pessoas idosas por ano. As projeções indicam que, em 2050, a população idosa será de 1,9 bilhão de pessoas ${ }^{(3)}$.

Em muitos países, a preocupação com os direitos desta população já vem ocorrendo há alguns anos. Em 1999, uma organização sem fins lucrativos revisou a situação das políticas nacionais sobre envelhecimento em 46 países. Desses, em apenas 19 observou-se a implantação dessas políticas, na prática. Em 2002, foram pesquisados 79 países; sendo que em 29 deles existiam políticas especificamente elaboradas para a população idosa e, outros 16 , estavam em processo de desenvolvimento. $O$ enfoque varia: alguns países optam por integrar os temas de envelhecimento a políticas sociais mais amplas, outros elaboram políticas específicas sobre o envelhecimento. 0 conteúdo varia, desde políticas que focalizam o bemestar e atenção, até enfoque baseado em direitos específicos dos idosos ${ }^{(4)}$.

No Brasil, essa preocupação também ocorre há vários anos, e vem acentuando-se cada vez mais, devido o aumento da expectativa de vida e, conseqüentemente, o aumento do número de idosos. O último Censo Demográfico feito pelo Instituto Brasileiro de Geografia e Estatística (IBGE) acusou que, no Brasil, a população com idade igual ou superior a 60 anos soma mais de 14,5 milhões de pessoas, $8,56 \%$ da população total, sendo que quase dois milhões estão acima dos 75 anos e, destes, cerca de 25 mil estão acima dos 100 anos. Chama a atenção que dessa população, que já viveu 100 anos ou mais, quase $90 \%$ são mulheres. Estima-se que em 2050 a população de idosos represente $18 \%$ do total de brasileiros, o que corresponderá à aproximadamente 47 milhões de idosos ${ }^{(3)}$.

O aumento da população idosa tornou mais evidente a necessidade de discutir os direitos desse grupo. Assim, no dia 10 de outubro de 2003, no Senado Fede- ral, foi sancionada a redação final do Estatuto do Idoso (EI) que garante que

o idoso goza de todos os direitos fundamentais inerentes à pessoa humana (...) assegurando-se-lhe, por lei ou por outros meios, todas as facilidades, para preservação de sua saúde física e mental, seu aperfeiçoamento moral, intelectual, espiritual e social, em condições de liberdade e dignidade.

Coloca, ainda, que seja

obrigação da família, da comunidade, da sociedade e do Poder Público assegurar ao idoso, com absoluta prioridade, a efetivação do direito à vida, à saúde, à alimentação, à educação, à cultura, ao esporte, ao lazer, ao trabalho, à cidadania, à liberdade, à dignidade, ao respeito e à convivência familiar e comunitária(5).

O Estatuto do Idoso contemplou as leis já existentes, organizou-as por tópicos, discorreu sobre cada um dos direitos e especificou as punições para os infratores, ficando mais prática sua compreensão e aplicação. Além disso, se for feita uma comparação detalhada das leis relativas ao idoso com o Estatuto do Idoso, constata-se que houve uma ampliação dos direitos. Por exemplo: no Código Nacional de Direitos dos Usuários das Ações e dos Serviços de Saúde ele está protegido como usuário comum, no Estatuto do Idoso ele é considerado prioridade.

Pode-se dizer que o tema central que permeia todos os artigos do Estatuto do Idoso é o amparo, a assistência e a proteção ao indivíduo em seu processo de envelhecimento e quando já velho. $O$ Estatuto esclarece sobre os deveres das famílias, das instituições, do governo e do cidadão comum em relação aos cuidados e apoio ao idoso. As mudanças sociais ocorridas no mundo industrializado acarretaram alterações na dinâmica da família moderna, refletindo na relação com os idosos. A mulher, por exemplo, não é mais responsável apenas, por cuidar da casa, dos filhos e dos pais idosos, mas, passou a exercer, também, um importante papel econômico na sociedade. Tornou-se mais comum o idoso ser cuidado por outro idoso, normalmente o cônjuge, que algumas vezes possui agravos em sua saúde e que, assumindo mais essa atividade, acarreta mudanças em sua vida. Quando questionados sobre que mudanças perceberam após terem se tornado cuidadores de seus cônjuges, um grupo de idosos disse ter aumentado o cansaço, stress, preocupação, aparecimento de sintomas e doenças, aumento dos riscos à saúde e mudanças no cotidiano e auto-estima, necessitando, muitas vezes, serem cuidados também ${ }^{(6)}$.

Isso demandou o aumento do número e diversificação das instituições especializadas no cuidado aos idosos, que podem ser Centros de Convivência, Centros de Cuidados Diurno, Hospitais-Dia, Casas-Lar, Instituições Asilares, Instituições de Longa Permanência para Idosos (ILPI) e outras formas inovadoras de moradias. 
Passou a ocorrer então, com maior freqüência, a institucionalização ou asilamento dos idosos, que pode acontecer por vários motivos: por escolha do próprio idoso (acreditando ser um peso e não querendo incomodar ou pela necessidade que sente de socializar-se com outras pessoas da sua idade), por escolha da família (tentando 'livrar-se do peso' ou acreditando que será realmente o melhor para seu familiar idoso, caso haja déficit do cuidador), ou por doença (nos casos em que o idoso precisa de acompanhamento clínico contínuo).

Ocorrendo a institucionalização, os laços de segurança e afetividade do idoso com a família poderão ser afetados e serão estabelecidos novos relacionamentos, com os outros idosos da instituição e com a equipe que lhe atenderá. Um estudo, escrevendo a respeito do relacionamento entre os idosos institucionalizados e a equipe multiprofissional, mostrou que os idosos caracterizaram a equipe multidisciplinar como um grupo que desenvolve ações dinâmicas e integradas, porém, a tônica do cuidado é dada pelo estabelecimento de relações afetivas entre o internado e a equipe que presta assistência(7).

Essa relação que se estabelece com o paciente não pode ser fruto da casualidade, mas deve ser baseada na capacidade do profissional. Devem ser evitadas atitudes paternalistas que tratam o idoso como se ele fosse uma criança irresponsável, bem como condutas de compaixão do tipo pobrezinho ou que pena. Essa postura nega ao idoso a sua individualidade, autonomia e independência ${ }^{(8)}$.

Com a nova dinâmica do cuidado aos idosos, demandam-se adaptações das famílias, dos programas governamentais, da sociedade, das instituições e, em especial, da equipe que atende essa população. Demandas essas, claramente contempladas pelo Estatuto do Idoso. Entretanto, torna-se necessário serem debatidas tais necessidades com os profissionais envolvidos no processo do cuidado aos idosos. Assim, este estudo objetivou verificar qual o contato da equipe multiprofissional com o Estatuto do Idoso e conhecer a percepção dessa equipe sobre a interferência do Estatuto do Idoso na assistência.

\section{MÉTODO}

Este estudo foi realizado com a equipe multiprofissional do Hospital Geriátrico e de Convalescentes Dom Pedro II (HGCDPII), mantido pela Irmandade da Santa Casa de Misericórdia de São Paulo (ISCMSP). Essa instituição presta assistência ambulatorial, em regime de institucionalização (a grande maioria) e internação, para idosos e convalescentes. Atende, atualmente, um total de 472 pacientes, com predominância de indivíduos com idade igual ou superior a 60 anos, que totalizam 297 idosos (62,9\%), sendo 119 homens $(40,1 \%)$ e 178 mulheres $(59,9 \%)$. A equipe multiprofissional do HGCDPII é composta por enfermeiros, médicos, fisioterapeutas, nutricionistas, as- sistentes sociais, fonoaudiólogos, odontólogos, farmacêutica e terapeuta ocupacional, que compuseram a população deste estudo.

Após autorização da instituição e aprovação do Comitê de Ética em Pesquisa (Processo n. 18/05), os profissionais foram convidados para participar do estudo. O convite foi feito pela pesquisadora, que explicou os objetivos do estudo e a forma de coleta dos dados. Esclareceu sobre a garantia do anonimato, a voluntariedade da participação, a devolução do questionário no envelope lacrado, a manutenção com o participante da cópia do termo de responsabilidade e sobre outras questões que surgiram sobre a pesquisa.

Aos profissionais que manifestaram interesse em participar, foi entregue um envelope contendo o instrumento de coleta de dados e o Termo de Responsabilidade assinado pela pesquisadora. Foi acordado com os profissionais um prazo para a devolução do instrumento, conforme a disponibilidade do profissional.

Foram distribuídos 52 questionários, sendo que 35 foram devolvidos preenchidos $(67,4 \%) ; 15$ não foram devolvidos (28,8 \%); e dois devolvidos em branco (3,8\%). Assim, a amostra foi constituída de 35 profissionais.

$\mathrm{O}$ instrumento de coleta de dados constou de itens relativos à caracterização dos participantes e de perguntas abertas e fechadas, que possibilitaram o alcance dos objetivos. Foi feita análise quantitativa dos dados, que permitiu a verificação da freqüência absoluta e relativa das respostas.

\section{ANÁLISE E DISCUSSÃO DOS RESULTADOS}

Os profissionais participantes do estudo somaram 35 : dez enfermeiros $(28,6 \%)$, dez médicos $(28,6 \%)$, cinco assistentes sociais $(14,3 \%)$, quatro nutricionistas $(11,3 \%)$, três fisioterapeutas $(8,6 \%)$, um terapeuta ocupacional (2,9\%), um odontólogo (2,9\%) e um farmacêutico (2,9\%). Desses profissionais, $19(54,4 \%)$ cursaram ou estão cursando pós-graduação lato sensu e stricto sensu em geriatria e gerontologia.

Quando questionados sobre terem lido o Estatuto do Idoso, 21 (60\%) afirmaram ter lido o documento por completo, $13(37,1 \%)$ referiram ter lido parcialmente e um profissional $(2,9 \%)$ referiu não ter lido.

Dos profissionais que participaram da pesquisa, 24 $(68,6 \%)$ acreditam que aconteceram mudanças na assistência ao idoso institucionalizado após a promulgação do El, nove $(25,7 \%)$ acreditam que as mudanças não ocorreram e dois $(5,7 \%)$ não se detiveram para considerar o assunto.

Foi solicitado aos 24 participantes, que afirmaram ter acontecido mudanças, que apontassem quais mudanças 
ocorreram. Dentre as citações, os respondentes, referiram que o maior número de mudanças ocorreu entre os próprios profissionais e na forma como esses passaram a prestar a assistência, seguido de mudanças institucionais e mudanças nas atitudes dos idosos e suas famílias.

\section{Mudanças ocorridas na equipe multiprofissional}

Dentre os comentários, dos 24 respondentes, relativos às mudanças ocorridas, citações relacionadas à capacitação e especialização da equipe multiprofissional foram as mais freqüentes, sendo citadas por 14 (58,3\%) dos profissionais. Segundo esses participantes, após a promulgação do El, houve maior busca na capacitação dos profissionais, o que possibilitou que o tratamento se tornasse mais direcionado e específico ao idoso.

Para que a clientela de idosos seja atendida adequadamente, existe a necessidade de capacitação de recursos humanos para atuar nas unidades geriátricas, sendo necessário que os profissionais recebam formação específica e de qualidade na área de geriatria e gerontologia social ${ }^{(9)}$.

É oportuna e necessária a capacitação da equipe, visto que atender ao idoso em suas particularidades é diferente de atender qualquer outro grupo etário, em especial se o idoso estiver institucionalizado, pois além de prestar os cuidados como membro da equipe multiprofissional, o profissional é a pessoa mais próxima do idoso, que fará papel de cuidador, familiar e amigo.

Sabe-se que o processo saúde-doença ocorre diferentemente de um indivíduo a outro, dependendo da capacidade do corpo de recuperar-se, da forma que a pessoa vivencia a doença, da esperança de restabelecimento que o indivíduo alimenta, entre outros fatores. Nos idosos, tratar de uma doença, mesmo que não seja específica da sua faixa etária, é diferente de tratar a mesma doença em um indivíduo jovem. Por exemplo, tratar uma ferida em um jovem é bem diferente de tratar essa mesma ferida em um idoso, pois o idoso possui os comprometimentos específicos de sua idade: sua pele não se regenera tão rapidamente, a circulação periférica ocorre com maior dificuldade, os fatores envolvidos na cicatrização operam mais lentamente, o que faz com que o seu tratamento necessite ser específico.

Um profissional que não seja conhecedor das particularidades envolvidas no tratamento de um idoso, não conseguirá identificar as especificidades de tratamento requeridas por essa população, o que acarretará em aumento do sofrimento do idoso e menos eficácia no tratamento.

Outro fator que contribui para o aumento da especificidade do atendimento a essa população, segundo dois $(8,4 \%)$ dos 24 respondentes, é a introdução de novas categorias profissionais na equipe multiprofissional que atende aos idosos. Dessa forma, é necessário que se criem e divulguem cursos de especialização em geriatria e gerontologia nas diferentes áreas de conhecimento, direcionados a enfermeiros, médicos, fisioterapeutas, nutricionistas, entre outros.

É notável a carência de profissionais qualificados parao cuidado ao idoso, em todos os níveis de atenção. É o que refere a Política Nacional de Saúde da Pessoa Idosa, e, em relação à educação de nível superior, afirma que é necessário discutir e readequar os currículos e programas de ensino e, ainda, criar Centros Colaboradores de Geriatria e Gerontologia,

que possam atuar de forma integrada com o SUS, mediante o estabelecimento de referência e contra-referência de ações e serviços para o atendimento integral dos indivíduos idosos e a capacitação de equipes multiprofissionais e interdisciplinares,

tendo como objetivo principal a qualificação contínua do pessoal de saúde nas áreas de gerência, planejamento, pesquisa e assistência à pessoa idosa ${ }^{(10)}$.

Quatro $(16,7 \%)$ dos 24 respondentes desta pesquisa referiram que a promulgação do El fez com que os idosos e seus familiares fossem mais rígidos nas cobranças do atendimento e, também, que os profissionais se tornassem mais preocupados e conscientes de seus deveres como cuidadores, levando-os a acreditar que essa situação possa ter incentivado a equipe a buscar a especialização.

O Estatuto do Idoso coloca que $A$ prevenção e a manutenção da saúde do idoso serão efetivadas por meio de: [...] pessoal especializado nas áreas de geriatria e gerontologia social (Art. $15, \S 1^{\circ}, \mathrm{III}$ ). Cumprindo-se a lei, o profissional está buscando especializar-se e o idoso está sendo mais bem assistido.

Esse anseio aumentou a preocupação dos profissionais com os aspectos legais da assistência. O receio de causar danos ao paciente durante o seu tratamento e sofrer alguma sanção jurídica, sempre foi bastante visível entre os profissionais da área de saúde. Após o estabelecimento de leis específicas de proteção aos indivíduos, como o Código de Defesa do Consumidor, o Estatuto da Criança e do Adolescente, a lei sobre os Direitos dos Usuários dos Serviços e das Ações de Saúde no Estado de São Paulo e o próprio Estatuto do Idoso, essa preocupação está mais evidente.

Segundo quatro $(16,7 \%)$ dos 24 participantes, uma das mudanças relacionadas ao valor legal do Estatuto do Idoso é justamente o aumento dessa preocupação dos profissionais em infringir leis e serem punidos. Referem que o profissional, querendo cumprir o El, por receio de cometer iatrogenias e sofrer sanções jurídicas, tornou-se mais cuidadoso na realização dos procedimentos com os pacientes.

A preocupação com o aspecto legal do El, não se restringe apenas à assistência direta ao paciente. Foram ci- 
tadas ainda, preocupações quanto à organização e manutenção em dia da documentação do paciente.

Sobre esse aspecto o El rege:

Art. 50. Constituem obrigações das entidades de atendimento: $[\ldots]$

XIII - providenciar ou solicitar que o Ministério Público requisite os documentos necessários ao exercício da cidadania àqueles que não os tiverem, na forma da lei; [...]

$\mathrm{XV}$ - manter arquivo de anotações onde constem data e circunstâncias do atendimento, nome do idoso, responsável, parentes, endereços, cidade, relação de seus pertences [...], e suas alterações, se houver, e demais dados que possibilitem sua identificação e a individualização do atendimento ${ }^{(5)}$.

É notório no HGCDPII o esforço em providenciar a documentação do paciente. Caso haja idosos que não possuam algum dos documentos exigidos por lei, por exemplo, o RG, o paciente é acompanhado até as instituições governamentais responsáveis pela emissão para providenciar o documento, fazendo com que o idoso possa ter assegurado seus direitos de cidadão, nos termos da lei. Cada vez mais, são elaborados e implantados novos instrumentos de registros, para que todos os dados referentes ao estado e evolução do paciente sejam devidamente documentados. Vivencia-se, atualmente, entre outras mudanças relacionadas aos registros das ocorrências com os pacientes, a implantação da Sistematização da Assistência de Enfermagem (SAE), que foi lembrada pelos respondentes da pesquisa, como forma de melhorar os registros dos cuidados de enfermagem. Criaram-se impressos específicos para o registro do exame físico, da evolução e prescrição de enfermagem, e a cada dia aumentam-se os esforços para que seja realizado o Processo de Enfermagem.

Um profissional $(4,2 \%)$ ressaltou que, pelo fato do El ser um documento oficial, a equipe multiprofissional ficou mais respaldada no momento de conscientizar as famílias. O El coloca que o idoso deve ser colocado como prioridade na efetivação de ações à saúde, à alimentação, à educação, à cultura, ao esporte, ao lazer, ao trabalho, à cidadania, à liberdade, à dignidade, ao respeito e à convivência familiar e comunitária, e impõe que A garantia de prioridade compreende: [...] priorização do atendimento do idoso por sua própria família, em detrimento do atendimento asilar (Art. 3ㅇ. § único, V). Não é porque o idoso está sob cuidados de alguma instituição que a família não possui mais responsabilidade pelo seu familiar. Na hora de incentivar a família a participar mais da vida e do tratamento do idoso institucionalizado, a equipe multiprofissional poderá fazer isso respaldada pela lei.

A especialização dos trabalhadores na área de geriatria e gerontologia e o aumento da preocupação com os aspectos legais levaram a mudanças e melhorias na assistência direta ao paciente.

\section{Mudanças ocorridas na assistência}

Os profissionais com capacitação específica em geriatria e gerontologia, passaram a preocupar-se mais com os direitos específicos dos idosos, levando a mudanças na assistência.

Para nove $(37,5 \%)$ dos 24 participantes que responderam ter ocorrido mudanças na assistência, está havendo uma maior preocupação do profissional com os direitos fundamentais dos idosos. O Estatuto do Idoso, nos artigos 2 ㅇ e 3 , dispõe que:

O idoso goza de todos os direitos fundamentais inerentes à pessoa humana, [..] é obrigação da família, da comunidade, da sociedade e do Poder Público assegurar ao idoso, com absoluta prioridade, a efetivação do direito à vida, à saúde, à alimentação, à educação, à cultura, ao esporte, ao lazer, ao trabalho, à cidadania, à liberdade, à dignidade, ao respeito e à convivência familiar e comunitária ${ }^{(5)}$.

Relataram estar ocorrendo maior preocupação com os direitos especificados nos artigos 20 e 3‥ Atividades de lazer e a prática de esporte foram lembradas por 5 $(20,8 \%)$ dos 24 respondentes. Em outra pesquisa, realizada na mesma instituição, cenário deste estudo, sobre o significado do lazer para o idoso institucionalizado, constatou-se que $68,2 \%$ dos pacientes entrevistados realizavam atividades de lazer e esporte quando jovens com idade entre 10 e 20 anos, ou seja, até serem inseridos no mercado de trabalho; outros $9,1 \%$ relataram praticar essas atividades somente após os 20 anos. Ao passarem pelo processo de envelhecimento, $59,1 \%$ dos idosos responderam que essas atividades foram interrompidas, sendo que, $46,2 \%$ não realizava atividades de lazer há mais de trinta anos ${ }^{(11)}$.

Atender ao idoso de forma integral é preocupar-se não apenas com todos os aspectos do processo saúde-doença que o mesmo enfrenta. É necessário atendê-lo em suas necessidades físicas, emocionais, espirituais e sociais, integrando-os com outras pessoas, em especial outros indivíduos da mesma faixa etária que a sua, proporcionando-Ihes atividades e ocupação. No HGCDPII são proporcionadas atividades aos idosos dentro da própria Instituição e fora dela. Dentro da instituição, eles realizam atividades integradoras, onde produzem artesanato, objetos de decoração e uso pessoal, como cachecóis e blusas, produzem, ainda, a maioria das fraldas que são utilizadas pelos internos do hospital. Com o apoio dos profissionais os idosos realizam atividades externas, como passeios ao zoológico, parques, cinema e pontos turísticos.

Respeitar aos idosos, é respeitá-los em sua integralidade, proporcionar-lhes atividades culturais, de lazer e educativas; poderem ser transportados de um lugar a outro com segurança e conforto, para que exerçam seu direito à liberdade; desenvolver ambiente de convívio pacífico, sendo assegurados o bem-estar e a efetivação do seu di- 
reito à vida. Dentro de uma ILPI, quem exerce a função de promotor desses direitos, é em grande parte a equipe multiprofissional, que permanece junto ao idoso mais tempo do que este passa com sua própria família.

Outra mudança citada por 10 (41,7\%) dos 24 participantes é o aumento da humanização e do respeito na assistência ao idoso. O termo humanização, geralmente emprega-se

para a forma de assistência que valorize a qualidade do cuidado do ponto de vista técnico, associada ao reconhecimento dos direitos do paciente, de sua subjetividade e referências culturais. Implica ainda a valorização do profissional e do diálogo intra e interequipes ${ }^{(12)}$.

Pode-se entender que para ocorrer a humanização na assistência do idoso é necessário que ele seja atendido, com prioridade, em sua totalidade e individualidade. $\mathrm{O} \mathrm{EI}$ rege que a garantia de prioridade no atendimento ao idoso, outorga-Ihe o direito a receber atendimento preferencial imediato e individualizado junto aos órgãos públicos $e$ privados prestadores de serviços à população ${ }^{(5)}$.

Para sete $(29,2 \%)$ dos 24 profissionais que acreditam ter ocorrido mudanças após a promulgação do El, outra mudança foi que os idosos, de modo geral, estão sendo atendidos, de forma mais humanizada, com mais respeito e menos preconceitos.

Outros conceitos, que estão diretamente ligados ao respeito da individualidade e humanização da assistência aos idosos, são o respeito à autonomia e a manutenção da sua independência, a humanização não poderá ocorrer de forma completa, se estes fatores não forem levados em conta.

O conceito de autonomia ${ }^{(13)}$ diz que:

uma pessoa autônoma é um indivíduo capaz de deliberar sobre seus objetivos pessoais e de agir na direção dessa deliberação.

É o direito de o indivíduo decidir sobre si mesmo. Diz ainda, que as convicções pessoais do idoso merecem ser respeitadas e discute que

é importante avaliar o grau de capacidade que a pessoa tem para tomar suas decisões. A sua participação ativa no processo de tomada de decisões é restringida, muitas vezes, pela própria família e pelas instituições.

Segundo um $(4,2 \%)$ dos 24 profissionais, que acreditam ter ocorrido as mudanças, o idoso está participando mais no processo de tomada de decisões sobre o seu tratamento e, também, que a família e o próprio idoso estão mais livres para acessarem o prontuário do paciente.

Acredita-se que o idoso exerce níveis de autonomia, que são determinados por sua capacidade funcional, ou capacidade para atividades da vida diária, mas, vale lembrar que autonomia não é ausência de dependência física ou social ${ }^{(14)}$.

\section{O Estatuto do Idoso coloca que}

O direito ao respeito consiste na inviolabilidade da integridade física, psíquica e moral, abrangendo a preservação da imagem, da identidade, da autonomia, de valores, idéias e crenças, dos espaços e dos objetos pessoais (Art. 10요 $\S 2^{\circ}$ ).

E complementa que a assistência nas instituições de longa permanência deverá ser baseada no princípio de preservação da identidade do idoso (Art. 49, VI).

No conceito de independência, o aspecto central é a capacidade funcional, onde o idoso realiza as atividades instrumentais da vida diária e de autocuidado. Quando se trata de dependência, esta pode não ser de pessoas, mas de medicações e equipamentos, como cadeira-deroda, marca-passo, e outros equipamentos ${ }^{(15)}$.

Idosos independentes possuem melhor qualidade de vida e vivem mais. A capacidade funcional (conseguir se locomover, raciocinar, realizar tarefas) é o principal fator relacionado à mortalidade entre idosos, o que faz com que a doença saia do primeiro plano das discussões sobre a saúde na terceira idade e passe a ser a principal discussão no processo de envelhecimento(16).

A dependência na velhice tem muitas faces e diferentes etiologias. Tem, também, diferentes conseqüências sobre as relações do idoso consigo próprio e com as outras pessoas, da mesma idade e de outras gerações; com o ambiente físico construído pelo homem; com o mundo natural e as instituições sociais. [...] Qualquer que seja a sua causa primária ou a combinação de causas que a determinam, o ambiente desempenha um papel importante na forma como vai se manifestar e em sua manutenção(17).

As pessoas que estarão diretamente ligadas ao idoso nesse processo, dentro das instituições asilares, são os membros da equipe multiprofissional. O ambiente vai depender do ajustamento da equipe no seu trabalho, no desenvolvimento dos papéis dos profissionais e, também, da estrutura que as instituições oferecem para a moradia do idoso e para a atuação profissional.

\section{Mudanças ocorridas nas instituições}

No Brasil, a portaria 810/89 do Ministério da Saúde, normatiza o funcionamento das instituições que atendem idosos. Dispõe sobre as normas para o funcionamento de casas de repouso, clínicas geriátricas e outras instituições destinadas ao atendimento de idosos:

Consideram-se como instituições específicas para idosos os estabelecimentos, com denominações diversas, correspondentes aos locais físicos equipados para atender pessoas com 60 (sessenta) ou mais anos de idade, sob regime de internato ou não, mediante pagamento ou não, durante um período indeterminado e que dispõem de um quadro de funcionários para atender às necessidades de cuidados com a saúde, alimentação, higiene, repouso e lazer dos usuários e desenvolver outras atividades características da vida institucional ${ }^{(18)}$ 
Esta portaria determina regras que devem ser aplicadas desde a construção, o funcionamento, até a equipe que prestará o atendimento direto ao paciente e foi complementada pelo El. Para $10(41,7 \%)$ dos 24 profissionais, após a promulgação do Estatuto, as instituições passaram por mudanças adaptativas para melhor atender a sua clientela e familiares.

Uma das mudanças é a adequação do quadro de profissionais. O Estatuto do Idoso rege que

constituem obrigações das entidades de atendimento:

[...]manter no quadro de pessoal profissionais com for-

mação específica (art. 50, XVII).

Se a preocupação com a qualidade de vida do idoso não ocorrer, os asilos somente farão com que os processos patológicos a que a velhice está sujeita, sejam acelerados $^{(17)}$. Isso porque os idosos demandam cuidados específicos. As instituições precisam adaptar-se para atenderem essas necessidades tanto no campo dos recursos humanos como na estrutura física.

As barreiras arquitetônicas constituem-se na maior dificuldade para os idosos exercerem em plenitude seu direito à liberdade, não apenas na rua, mas dentro de suas próprias casas. A falta de corrimãos, de pisos antiderrapantes, ou a presença de degraus, tapetes e portas estreitas torna difícil a locomoção do idoso. As famílias, ao construírem seus lares, algumas vezes, não pensam que podem envelhecer dentro daquela casa, e algo que hoje é motivo de grande orgulho, como uma casa com grandes escadarias, pisos polidos e brilhantes, amanhã poderá ser motivo de grande penar, pois envelhecendo poderá sentir-se preso dentro da sua própria moradia.

Essa preocupação existe também nas instituições, que buscam adaptarem sua estrutura física para atender aos idosos. O Estatuto do Idoso coloca que

As instituições que abrigarem idosos são obrigadas a manter padrões de habitação compatíveis com as necessidades deles [...] e a oferecer instalações físicas em condições adequadas de habitabilidade (Art. 37, $\S 3^{\circ} \mathrm{e}$ art. 50, IV).

Foi citada, por um participante $(4,2 \%)$ dos 24 respondentes, a criação de um local específico e adequado para que o idoso receba suas visitas, que também consta no artigo 50, inciso VII, do El. Quando institucionalizado, a ILPI é o lar do idoso e ele precisa, com liberdade e privacidade, poder receber visita em um local confortável e adequado para isso, o que promove a integração do idoso com o mundo externo.

Essas mudanças podem ocorrer por iniciativa da instituição, ou por cobrança do paciente e seus familiares.

\section{Mudanças ocorridas nas atitudes dos idosos e suas famílias}

Outra mudança referida por quatro $(16,7 \%)$ dos 24 respondentes foi a maior reinvidicação dos direitos do idoso pelo próprio idoso e por sua família. Da mesma forma, a família está mais preocupada com o dever de cumpri-lo, buscando aproximação e manutenção dos vínculos familiares, mesmo quando o idoso estiver institucionalizado.

Sobre o relacionamento entre a família e o idoso, o Estatuto coloca que a ILPI deve possuir como princípio a manutenção dos vínculos familiares, e no art. 16 dispõe que

ao idoso internado ou em observação é assegurado o direito a acompanhante, devendo o órgão de saúde proporcionar as condições adequadas para a sua permanência em tempo integral, segundo o critério médico.

O que deve ocorrer é um trabalho conjunto entre a instituição, a equipe multiprofissional e a família, em prol do benefício do idoso.

\section{CONCLUSÕES}

O Estatuto do Idoso foi recebido com otimismo pelos idosos e com expectativa pelos profissionais. Na prática, o Estatuto do Idoso está trazendo resultados positivos na assistência ao idoso institucionalizado, como foi demonstrado nesta pesquisa:

- A grande maioria dos participantes afirmou ter lido o Estatuto do Idoso, por completo ou parcialmente.

- A maioria dos profissionais acredita ter ocorrido mudanças na assistência ao idoso institucionalizado, após a promulgação do El.

- As mudanças mais citadas estão relacionadas à capacitação e especialização da equipe multiprofissional.

- Outras mudanças citadas, com menor freqüência, foram que as instituições passaram por mudanças adaptativas para melhor atender a sua clientela e familiares; passou a ocorrer maior reinvidicação dos direitos do idoso pelo próprio idoso e por sua família e, além disso, a família está mais preocupada com o cumprimento do El.

Percebe-se que a conscientização dos profissionais, famílias e idosos está ocorrendo, que algumas mudanças já aconteceram, restando apenas, que cada um cumpra seu papel de cidadão, para garantir aos idosos o cumprimento da sua cidadania. 


\section{REFERÊNCIAS}

1. Cícero MT. Saber envelhecer e A amizade. Trad. de Paulo Neves. Porto Alegre: L \& PM; 1999.

2. Shakespeare W. O Rei Lear. Porto Alegre: L \& PM; 1997.

3. Instituto Brasileiro de Geografia e Estatística (IBGE). Perfil dos idosos responsáveis pelos domicílios no Brasil - 2000. Rio de Janeiro; 2002.

4. HelpAge International. Acción Global sobre Envejecimiento. Estado mundial de las personas mayores 2002 [texto na Internet]. Londres; 2002. [citado 2007 jan. 15]. Disponível em: http://www.helpage.org/es/Global/America Latina-1/Materiales

5. Brasil. Lei n. 10.741, de 1 o de outubro de 2003. Dispõe sobre o Estatuto do Idoso e dá outras providências. Diário Oficial da União, Brasília, 3 out. 2003. Seção 1, p. 1.

6. Rodrigues SLA, Watanabe HA, Derntl AM. A saúde de idosos que cuidam de idosos. Rev Esc Enferm USP. 2006;40(4):493-500.

7. Ferreira MH. Compreendendo o idoso institucionalizado: um estudo etnográfico. Belo Horizonte: [s.n.]; 1999.

8. Ruiperez Cantera I, Llorente Domingo P. Geriatria. Trad. de Maria Teresa Ramalhal Teixeira. Rio de Janeiro: McGraw-Hill do Brasil; 2002.

9. Fiorin JL. Elementos de análise do discurso. São Paulo: Contexto/EDUSP; 1989.

10. Marziale MHP. A política nacional de atenção ao idoso e a capacitação dos profissionais de enfermagem [editorial]. Rev Lat Am Enferm. 2003;11(6):701-2.
11. Brasil. Ministério da Saúde. Portaria n. 2.528, de 19 de outubro de 2006. Aprova a Política Nacional de Saúde da Pessoa Idosa. Diário Oficial da União, Brasília, 20 out. 2006. Seção 1, p. 142.

12. Faustino AM, Tavares MFT, Pereira MJCVL. O significado do lazer para o idoso institucionalizado [monografia]. São Paulo: Departamento de Enfermagem, Escola Paulista de Medicina, Universidade Federal de São Paulo; 2004.

13. Deslandes SF. Análise do discurso oficial sobre a humanização da assistência hospitalar. Ciênc Saúde Coletiva. 2004;9(1):7-14.

14. Goldim JR. Bioética e envelhecimento. In: Freitas EV, Py L, Neri AL, Cançado FAX, Gorzoni ML, Rocha SM. Tratado de geriatria e gerontologia. Rio de Janeiro: Guanabara Koogan; 2002.

15. Neri AL. Palavras-chave em gerontologia. Campinas: Alínea; 2001

16. Siqueira LEA. Estatuto do idoso de A a Z. Aparecida, SP: Idéias e Letras; 2004.

17. Lemos N, Medeiros SL. Suporte social ao idoso dependente. In: Freitas EV, Py L, Neri AL, Cançado FAX, Gorzoni ML, Rocha SM. Tratado de geriatria e gerontologia. Rio de Janeiro: Guanabara Koogan; 2002.

18. Brasil. Portaria n. 810. Aprova as normas e padrões para o funcionamento de casas de repouso, clínicas geriátricas e outras instituições destinadas ao atendimento de idosos. Diário Oficial da União, Brasília, 27 set. 1989. Seção 1, p. 17297-8. 